\title{
How does stigma affect people with psoriasis?
}

\author{
Patryk Łakuta ${ }^{1}$, Kamil Marcinkiewicz², Beata Bergler-Czop³ ${ }^{3}$ Ligia Brzezińska-Wcisło ${ }^{3}$
}

1SWPS University of Social Sciences and Humanities, Warsaw, Poland

${ }^{2}$ Institute of Cardiology, Warsaw, Poland

${ }^{3}$ Departament of Dermatology, Medical University of Silesia, Katowice, Poland

Adv Dermatol Allergol 2017; XXXIV (1): 36-41

DOI: https://doi.org/10.5114/pdia.2016.62286

\begin{abstract}
Introduction: Psoriasis is associated with a major additional psychological burden.

Aim: To investigate whether the extent of skin involvement, stigmatization, and perceived social support are related to depressive symptoms in psoriasis patients.

Material and methods: One hundred and forty-eight psoriasis patients completed in the BSA, the Beck Depression Inventory, Stigmatization Scale, and Multidimensional Scale of Perceived Social Support.

Results: Almost $13 \%$ of participants obtained a BDI total score indicating moderate depressive symptoms. The results of regression analysis revealed that greater depression severity in psoriasis patients is associated with higher levels of psoriasis-related stigma, lower perceived social support, female gender and a shorter duration of the disease, explaining $43 \%$ of the variance of depression. The stigmatization was the most powerful predictor of depressive symptoms for psoriasis patients and accounted for $33 \%$ of the variance.

Conclusions: The extent of psoriasis does not directly lead to mood disturbance in these patients. Rather, social stigma accounted for this relationship. Strategies for reducing the stigma attached to patients with psoriasis are required.
\end{abstract}

Key words: psoriasis, depression, stigma, social support.

\section{Introduction}

Psoriasis is a chronic, immune-dependent and inflammatory skin disease, affecting men and women equally. Prevalence estimates suggest the incidence of psoriasis is approximately $2 \%$ of the general population [1]. In developed countries the incidence of illness is estimated at about $4.6 \%$ [1]. Psoriasis may involve all sites of the body and has a serious impact on the patients' lives and well-being [2-5]. That impact is often higher than in other chronic diseases [6].

Burden of the disease extends beyond the physical symptoms experienced by patients. These components are rarely recognized among clinicians [7]. Previous studies accentuated a disconcertingly high percentage of various psychological problems in this group [3, 4]. Problems in daily life including experiences of humiliation and rejection, negative impact on the employment capacity, career prospects and earning potential, contribute to the cumulative impact of psoriasis on patients' lives [2-4]. Stigmatization and other social difficulties may exacerbate negative emotions, maladaptive thought processes (e.g. defectiveness), unfavourable self-perceptions (e.g. lowered self-esteem and negative body image), and neg- ative behaviour patterns (e.g. excessive social avoidance). Consequently, psychosocial comorbidities including depression, suicide ideation, anxiety, sexual dysfunctions, and alcohol addiction are fairly common among psoriasis patients $[3,8,9]$. Accumulation of physical, psychological, socioeconomic burden across a lifetime, along with the impact of psoriasis on minor and major life-changing decisions, has the potential to change substantially the trajectory of a patient's life so that it differs highly from what it might have been in the absence of the disease $[3,4]$. Nevertheless, depression and other psychosocial comorbidities are not always proportional to the disease severity. Studies which examine the impact of psoriasis on patients' lives indicate that the relationship between the severity of the disease and the degree of deterioration in quality of life and mental health of patients is weak [10-12].

Based on the Stress-Coping Model of Maes et al. [13], patient's own underlying perceptions of illness, body shame, and negative experiences of social interaction may have a particular importance in coping with the disease. These factors are often unexplored by physicians. Moreover, Tabolli et al. found that patients and physicians may differ in the assessment of the disease

Address for correspondence: Patryk Łakuta PhD student, SWPS University of Social Sciences and Humanities, Warsaw, Poland 19/31 Chodakowska St, 03-815 Warsaw, Poland, phone: +48 50013 52 87, e-mail: patryk.lakuta@gmail.com Received: 14.12 .2015 , accepted: 14.01.2016. 
severity [14]. Divergent assessments and beliefs about the impact of psoriasis on patients' day-to-day life can affect the doctor-patient relationship, and health care through unwillingness to the health care system, or distrust of prescribed therapies [15]. Thus, in this study we emphasize the importance of the role of patients' subjective assessment of the disease severity.

Furthermore, for this group of patients social support may be of particular importance. As was mentioned earlier, skin diseases such as psoriasis still arouse aversion and intolerance $[2-4,16]$. We assumed that social support might be a substantial factor buffering the negative consequences of the diseases such as stigmatization and relegation to the fringe of society. Friends and relatives providing support resulting in enhanced self-esteem and approval may play an important role in better adaptation to the disease [17].

\section{Aim}

This study examined the role of subjective assessment of severity and symptoms perception, experiences of stigmatization, perceived social support in depressive symptoms among patients with psoriasis.

\section{Material and methods}

\section{Participants and procedure}

This study was conducted among psoriasis outpatients. Self-report questionnaires with instructions for completing were distributed over the Internet in cooperation with 6 psoriasis associations from all over Poland. Besides, a paper version was available to those patients without access to the Internet. To obtain permission to participate in the study, patients were provided with information about the purpose and scope of the study. The survey was anonymous, no incentive has been offered. The inclusion criteria were age $\geq 18$ years and diagnosed psoriasis. A medical ethics review was not required according to the local Medical Review Ethics Committee. The recruitment took place between November 2014 and December 2014. The Internet-based surveys have become more popular in the recent years. Relevant advantages of Internet-based surveys concern to not being dependent on keeping appointments, increased disclosure and decreased social desirability bias [18]. Overall, findings show that paper-and-pencil and Internet data collection methods are generally equivalent and may serve as an advantageous and reliable methodology $[19,20]$.

\section{Measures}

\section{Beck Depression Inventory (BDI)}

The BDI is a self-report scale consisting of 21 items about how the subject has been feeling in the last
2 weeks. Each of the 21 items corresponding to symptoms of depression is summed to give a total score for the BDI. Higher total scores indicate more severe depressive symptoms [21, 22]. The Polish validated version shows good reliability and content validity [23]. The score of 0-11 indicates no or minimal depression; $12-26$ mild depression; 27-49 moderate depression; and 50-63 severe depression. The reliability of the BDI in the present study was $\alpha=0.92$.

\section{Stigmatization Scale}

The Stigmatization Scale is a 6-item scale assessing the stigmatization caused by skin conditions [24]. Items are rated on a 4-point scale, ranging from 0 (Not at all) to 3 (Always), with higher scores reflecting greater experiences of stigmatization (total scores can range from 0 to 18). The Polish validated version of the scale was used [25]. Internal consistency of the scale in the current sample was $\alpha=0.88$.

\section{Multidimensional Scale of Perceived Social Support (MSPSS)}

The MSPSS is a 12-item self-report measure assessing the perceived support from three domains: family, friends, and a significant other. The participants completing the MSPSS are asked to indicate their agreement with the items on a 7-point Likert-type scale, ranging from 'very strongly disagree' to 'very strongly agree'. The sum of the three domains shows a global satisfaction with perceived social support. The MSPSS has proven to be psychometrically sound in diverse samples and to have good internal reliability, test-retest reliability, and robust factorial validity $[26,27]$. In the current study internal consistency was good: $\alpha=0.95, \alpha=0.91, \alpha=0.95$ and $\alpha=0.95$ for Significant Other, Family, Friends, and Total support scales, respectively.

\section{Body surface involvement}

As in previous web-based studies [12, 28], the extent of psoriasis was defined based on self-reported body surface area involvement. Respondents were requested to estimate the surface area of their skin affected by psoriasis as a percentage of their total body surface, using the approximation that the palm of one hand represents $1 \%$ of the body surface area. Body surface area (BSA) is a simple and commonly used measure assessing the percentage of body surface involvement [12, 28, 29]. Mild involvement of skin with psoriasis is defined as 1-10\% BSA, moderate to severe involvement >10\% BSA [30].

\section{Additional questions}

The items about medical data (as recognized by professionals: type of psoriasis, age at onset, the duration of the disease) and subjective evaluation of the effectiveness 
Table 1. Sample characteristics $(N=148)$

\begin{tabular}{lc}
\hline Parametr & Result \\
\hline Sex, $n$ (\%): & $104(70.3)$ \\
\hline Female & $44(29.7)$ \\
\hline Male & $34.6 \pm 11.8$ \\
\hline Age, mean \pm SD [years] & \\
\hline Marital status, $n$ (\%): & $53(35.8)$ \\
\hline Single & $78(52.7)$ \\
\hline Married/cohabiting & $12(8.1)$ \\
\hline Divorced & $5(3.4)$ \\
\hline Widowed & $102(68.9)$ \\
\hline Work, $n$ (\%): & $11(7.4)$ \\
\hline Employed & $21(14.2)$ \\
\hline Unemployed & $14(9.5)$ \\
\hline Student & $134(90.5)$ \\
\hline Retired & $3(2.0)$ \\
\hline Psoriasis, $n$ (\%): & $30(20.3)$ \\
\hline Plaque & $28(18.9)$ \\
\hline Erythrodermic & $58(39.2)$ \\
\hline Pustular & $18.6 \pm 10.2$ \\
\hline Psoriatic arthritis & $16.1 \pm 11.7$ \\
\hline Nail psoriasis & $20.8(0-82)$ \\
\hline Age at onset of psoriasis, mean \pm SD [years] & \\
\hline Duration of psoriasis, mean \pm SD [years] & $(58.8)$ \\
\hline BSA (body surface area), mean (range) & \\
\hline BStent of skin involvement, $n$ (\%): & $10 \%$ \\
\hline
\end{tabular}

of the treatment were covered in the questionnaire. The remaining questions concerned the impact of psoriasis on patients' life. Items were rated on a 5-point scale, ranging from 1 (Completely disagree) to 5 (Completely agree).

\section{Statistical analysis}

The data were analyzed using the statistical package Statistica, version 10 (StatSoft Inc.). Mann-Whitney $U$-test was used for group comparisons (the analyzed groups differed in size). Also, the effect size ( $r$ ) was estimated. Effect sizes of 0.1, 0.3, and 0.5 are termed small, medium, and large, respectively [30]. Multiple regression analysis was used to identify predictors of depression in psoriasis patients.

\section{Results}

\section{Patient characteristics}

The final sample consisted of 148 psoriasis outpatients, 104 women and 44 men. Sociodemographic and clinical characteristics of the sample are given in Table 1. Participants' age range was $20-67$ years $(M=34.64$, $S D=11.82$ ). The mean age at onset of psoriasis was 18.57 \pm 10.24 years, varying between 0 and 54 years of age. The mean duration of the disease was $16.07 \pm 11.65$ years. Plaque psoriasis was the most common clinical type of psoriasis, which was present in 134 (90.5\%) cases. Almost half of the respondents (45\%) reported several types of psoriasis. Nail psoriasis occurred in $39 \%$ of participants. Sixty-one (41\%) patients reported mild psoriasis (BSA $\leq$ $10 \%$ ) and eighty-seven (59\%) reported moderate to severe psoriasis (BSA > 10\%).

Most participants (60\%) were not satisfied with the effectiveness of their treatment. Forty-three (30\%) patients reported that their psoriasis had a strong impact on their family life, sixty-one (41\%) reported negative impact on social life and forty (27\%) on work and career. At the time of the study, 67 (45.3\%) patients presented mild depressive symptoms, and 19 (12.8\%) presented moderate depressive symptoms as defined by the BDI.

\section{Comparison of women and men with psoriasis}

No significant differences were found between men and women (Mann-Whitney U-test: $p>0.05$ ). The results are shown in Table 2. Both women and men had similar levels of perceived social support from family, friends, and a significant other. Also, the groups did not differ significantly in age, extent of the disease, experiences of stigmatization, and duration of the disease. With respect to the BDI, women had higher BDI scores than men, indicating more severe depressive symptoms, although the observed differences were not statistically significant ( $p=0.09$ ), the calculated effect size is 0.14, which is considered "small". It is not particularly big, but it is certainly nontrivial [31].

\section{Predictors of depression in psoriasis patients}

A stepwise multiple regression was used to identify predictors of depression. This multiple regression analysis examined the total score of the BDI as the dependent variable, with sex, extent of psoriasis, duration of the disease, perceived global social support and experiences of stigmatization as independent variables (Table 3).

Regression analysis revealed that female $\operatorname{sex}(\beta=0.17$, $p<0.01)$, duration of the disease $(\beta=-0.15, p<0.05)$, perceived global social support $(\beta=-0.30, p<0.0001)$ and experiences of stigmatization $(\beta=0.50, p<0.00001)$ were significant predictors of depressive symptoms, explaining $43 \%$ of the variance of depression. The stigmatization was the most powerful predictor of depression and accounted for $33 \%$ of the variance. The extent of the disease (BSA) did not make a significant contribution to the variance in depressive symptoms ( $p=0.090$ ). Summarizing, the regression analysis indicated that greater depression severity in psoriasis patients is associated with higher levels of psoriasis-related stigma, lower perceived 
Table 2. Comparison of women and men with psoriasis

\begin{tabular}{|c|c|c|c|c|c|}
\hline \multirow[t]{2}{*}{ Parameter } & \multirow{2}{*}{$\frac{\text { Women }(n=104)}{\text { Mean rank }}$} & \multirow{2}{*}{$\frac{\text { Men }(n=44)}{\text { Mean rank }}$} & \multirow{2}{*}{$\begin{array}{c}\text { Mann-Whitney } \\
U \text {-test }\end{array}$} & \multirow[t]{2}{*}{$P$-value } & \multirow[t]{2}{*}{$r$} \\
\hline & & & & & \\
\hline Age & 73.2 & 77.5 & 2155.0 & 0.58 & 0.05 \\
\hline Extent of psoriasis (BSA) & 74.9 & 73.6 & 2248.0 & 0.87 & 0.01 \\
\hline Duration of the disease & 74.6 & 74.2 & 2276.0 & 0.96 & 0.00 \\
\hline Experiences of stigmatization & 74.9 & 73.5 & 2244.0 & 0.85 & 0.02 \\
\hline Depression & 78.4 & 65.3 & 1881.0 & 0.09 & 0.14 \\
\hline Family social support & 75.7 & 71.6 & 2159.5 & 0.59 & 0.04 \\
\hline Friend social support & 77.7 & 66.9 & 1952.5 & 0.16 & 0.12 \\
\hline Significant other social support & 77.6 & 67.1 & 1964.5 & 0.17 & 0.11 \\
\hline Global perceived social support & 77.7 & 66.9 & 1952.0 & 0.16 & 0.12 \\
\hline
\end{tabular}

social support, female gender, and a shorter duration of the disease.

\section{Discussion}

The results of the present study revealed that greater depression severity in patients with psoriasis is associated with higher levels of stigmatization, lower perceived social support, female gender, and a shorter duration of the disease.

Stigmatization emerged as the most powerful predictor of depressive symptoms for psoriasis patients. It is worth noting that stigmatization is related to the fear of social rejection and deprivation of the basic need for belonging [32]. Experiences of humiliation may have a high impact on patient's self-esteem, which in turn might contribute to developing negative self-beliefs about themselves. Chronicity of the rejection and stigmatization may lead to painful and negative emotions (particularly sadness, loneliness, and anger), and in consequence, as we have pointed out, negative mental health outcomes.

Stigmatizing attitudes toward people with psoriasis may be due to lack of knowledge. Psoriasis is still perceived as contagious disease and a result of poor personal hygiene [33]. Therefore, according to Weiner's attributional theory, the more a person is assessed as responsible for their condition, the higher affective reactions of hostility and anger prevail and the stronger the rejection is [34, 35]. Feelings of shame and stigmatization can lead to social avoidance and withdrawal, which in turn might result in a smaller social support network and the capability of receiving adequate support. Picardi et al. [36] pointed out that patients with psoriasis compared to those with other dermatological diseases, reported lower levels of perceived social support. The social support, as important social resources for an individual to cope with stressful life events, can buffer psychological distress and have beneficial effects on people's mental health [17]. Correspondingly, our findings indicate that higher
Table 3. Results of multiple regression analysis of depression $(N=148)$

\begin{tabular}{lcccc}
\hline Variable & \multicolumn{5}{c}{ Depression } \\
\cline { 2 - 5 } & $\beta$ & $\Delta R^{2}$ & $F$ & $P$-value \\
\hline Experiences of stigmatization & 0.50 & 33.3 & 72.89 & $<0.00001$ \\
\hline Global social support & -0.30 & 5.7 & 13.59 & $<0.0001$ \\
\hline Sex (female) & 0.17 & 2.7 & 6.67 & 0.009 \\
\hline Duration of the disease & -0.15 & 1.9 & 4.88 & 0.021 \\
\hline BSA & 0.11 & 1.1 & 2.92 & NS \\
\hline Model characteristics & Adj. $R^{2}=0.43 ; F(5,142)=23.0 ;$ \\
& \multicolumn{5}{c}{$p<0.00001$} \\
\hline
\end{tabular}

perceived social support is related to lower risk of depressive symptoms in psoriasis patients. Social support may provide a counterweight to negative experiences through reminder that an individual has important, supportive relationships and, thus, it helps to restore a sense of belonging.

The findings from the regression analysis also showed that women have a higher risk of depressive symptoms. This result is in line with some previous outcomes suggesting that women may suffer more from psoriasis than men [29]. Psoriasis is a disease closely related to appearance concerns, and therefore, presented outcome may be due to appearance norms for women which are more rigid, homogeneous and pervasive than those for men [37]. It should be emphasized that women are more frequently valued and assessed by their appearance than men $[38,39]$. Thus, especially among women suffering from psoriasis, everyday exposure to norms and social pressure may exacerbate negative emotions, maladaptive thoughts, and in consequence negative mental health outcomes. The cognitive processes linking selfimage, illness representation, beliefs about impression formation and the reactions of others seem to be main problems to be considered in further research. 
In line with previous studies [10, 11, 29, 40], there was no significant relationship between the disease severity and depression. Thus, severity of psoriasis is a weak predictor of depression in psoriasis patients. But, we noted that duration of the disease was inversely related to the BDI scores. The result suggests that the disease duration might be related to lower levels of depression and better adaptation to living with the disease. A somewhat different result was obtained in previous research [40]. The disease duration had been found to be unrelated to depressive symptoms. Further studies are needed to provide a better insight into the associations between duration of psoriasis, depressive symptoms, adaptation and acceptance of life with the disease.

In addition to physical problems, psoriasis significantly affects mental and emotional functioning. The results of our study suggest that nearly $13 \%$ of participants obtained a BDI total score indicating moderate depressive symptoms. Physicians should increase awareness of the broad impact of psoriasis on patients' life. Recognition of the psychological impact of psoriasis seems to be essential as the first step towards improving care. It is important to evaluate the symptoms of depressive disorders in patients with psoriasis, as they represent substantial morbidity that can be improved with a variety of pharmacological and nonpharmacological approaches.

Psychosocial burden is rarely reflected by physicians' objective assessment of the severity of psoriasis [7, 10] and, as a result, the overall severity of the disease may be underestimated. Patients are constructing their own representation of illness according to their experiences, personal world views and social contexts [13], which may result in divergent beliefs and expectations in the physician-patient relationship. Agreement between the clinician and the patient is a key factor that may influence health outcomes [15].

When interpreting the findings of our study, several limitations have to be kept in mind. This study was conducted over the Internet. Web-based surveys might serve as an advantageous and reliable methodology, and allow to decrease possible social desirability bias $[19,20]$. There are, however, some limitations while conducting surveys over the Internet. In this data collection method only selfreported measure of the extent of the disease might be obtained. Similarly, as in previous studies [12, 28], subjective assessments based on body surface coverage have been used. The BSA enables to define the body surface area affected, but is not a complete assessment of disease severity. Objective measures of the extent of psoriasis would be preferable. Future research might extend the current results taking into account the assessment of psoriasis severity measured by clinician and patient's self-report. A subsequent limitation of our study is a relatively small sample of men with psoriasis, women accounted for $70 \%$ of the sample. Men may show different patterns of results, which should be investigated in further research. Moreover, the cross-sectional design of the present study does not allow for causal conclusions. Consequently, replication is warranted.

\section{Conclusions}

This study provides some insight into the relationship between the extent of psoriasis and depression. Our findings highlight that patients with psoriasis with low perceived social support and high levels of experiences of stigmatization have a higher risk of depressive symptoms. Therefore, identifying patients receiving low social support, with strong experiences of stigmatization may help to recognize those people who are at risk for depression. Moreover, reducing stigma and discrimination related to skin disorders seems to be an indispensable step towards improving mental health in patients with psoriasis.

\section{Acknowledgments}

The authors thank all Polish psoriasis associations, mainly the Polish Association of Psoriasis Patients in Bydgoszcz.

\section{Conflict of interest}

The authors declare no conflict of interest.

\section{References}

1. Parisi R, Symmons DPM, Griffiths CEM, Ashcroft DM. Global epidemiology of psoriasis: a systematic review of incidence and prevalence. J Invest Dermatol 2013; 133: 377-85.

2. Ayala F, Sampogna F, Romano GV, et al. The impact of psoriasis on work-related problems: a multicenter cross-sectional survey. J Eur Acad Dermatol Venereol 2014; 28: 1623-32.

3. Kimball A, Gieler U, Linder D, et al. Psoriasis: is the impairment to a patient's life cumulative? J Eur Acad Dermatol Venereol 2010; 24: 989-1004.

4. Warren RB, Kleyn CE, Gulliver WP. Cumulative life course impairment in psoriasis: patient perception of disease-related impairment throughout the life course. Br J Dermatol 2011; 164 (Suppl. 1): S1-14.

5. Owczarek K, Jaworski M. Quality of life and severity of skin changes in the dynamics of psoriasis. Adv Dermatol Allergol 2016; 33: 102-8.

6. Rapp SR, Feldman SR, Exum ML, et al. Psoriasis causes as much disability as other major medical diseases. J Am Acad Dermatol 1999; 41: 401-7.

7. Moon HS, Mizara A, McBride SR. Psoriasis and psycho-dermatology. Dermatol Ther (Heidelb) 2013; 3: 117-30.

8. Dowlatshahi EA, Wakkee M, Arends LR, Nijsten T. The prevalence and odds of depressive symptoms and clinical depression in psoriasis patients: a systematic review and metaanalysis. J Invest Dermatol 2014; 134: 1542-51.

9. Dalgard FJ, Gieler U, Tomas-Aragones L, et al. The psychological burden of skin diseases: a cross-sectional multicenter study among dermatological out-patients in 13 European countries. J Invest Dermatol 2015; 135: 984-91. 
10. Kirby B, Richards HL, Woo P, et al. Physical and psychologic measures are necessary to assess overall psoriasis severity. J Am Acad Dermatol 2001; 45: 72-6.

11. Richards HL, Fortune DG, Griffiths CE, Main CJ. The contribution of perceptions of stigmatisation to disability in patients with psoriasis. J Psychosom Res 2001; 50: 11-5.

12. Schmitt JM, Ford DE. Role of depression in quality of life for patients with psoriasis. Dermatology 2007; 215: 17-27.

13. Maes S, Leventhal H, de Ridder D. Coping with chronic diseases. In: Handbook of coping. Ziender M, Endler N (eds.). John Wiley \& Sons, Chichester 1996; 221-51.

14. Tabolli S, Sampogna F, Pagliarello C, et al. Disease severity evaluation among dermatological out-patients: a comparison between the assessments of patients and physicians. J Eur Acad Dermatol Venereol 2012; 26: 213-28.

15. Ha J, Longnecker N. Doctor-patient communication: a review. Ochsner J 2010; 10: 38-43.

16. Hrehorów E, Salomon J, Matusiak L, et al. Patients with psoriasis feel stigmatized. Acta Derm Venereol 2012; 92: 67-72.

17. Cohen S. Social relationships and health. Am Psychol 2004; 59: 676-84.

18. Whitehead LC. Methodological and ethical issues in Internet-mediated research in the field of health: an integrated review of the literature. Soc Sci Med 2007; 65: 782-91.

19. Rhodes SD, DiClemente RJ, Cecil H, et al. Risk among men who have sex with men in the United States: a comparison of an Internet sample and a conventional outreach sample. AIDS Educ Prev 2002; 14: 41-50.

20. Weigold A, Weigold IK, Russell EJ. Examination of the equivalence of self-report survey-based paper-and-pencil and internet data collection methods. Psychol Methods 2013; 18: 53-70.

21. Beck AT, Ward CH, Mendelson M, et al. An inventory for measuring depression. Arch Gen Psychiatry 1961; 4: 561-71.

22. Beck AT, Steer RA, Garbin MG. Psychometric properties of the Beck Depression Inventory: twenty-five years of evaluation. Clin Psychol Rev 1988; 8: 77-100.

23. Parnowski T, Jernajczyk W. Inwentarz Depresji Becka w ocenie nastroju osób zdrowych i chorych na choroby afektywne [Beck's Depression Inventory in the rating of mood in normal subjects and in patients with affective disturbances]. Psychiatr Pol 1977; 11: 417-25.

24. Lu Y, Duller P, van der Valk PGM, Evers AWM. Helplessness as predictor of perceived stigmatization in patients with psoriasis and atopic dermatitis. Dermatol Psychosom 2003; 4: 146-50.

25. Hrehorów E, Szepietowski J, Reich A, et al. Instruments for stigmatization evaluation in patients suffering from psoriasis: Polish language version. Dermatol Klin 2006; 8: 253-8.

26. Zimet GD, Dahlem NW, Zimet SG, Farley GK. The multidimensional scale of perceived social support. J Pers Assess 1988; 52 1: 30-41.

27. Dahlem NW, Zimet GD, Walker RR. The multidimensional scale of perceived social support: a confirmation study. J Clin Psychol 1991; 47: 756-61.

28. Dubertret L, Mrowietz U, Ranki A, et al. European patient perspectives on the impact of psoriasis: the EUROPSO patient membership survey. Br J Dermatol 2006; 155: 729-36.

29. Finzi A, Colombo D, Caputo A, et al. Psychological distress and coping strategies in patients with psoriasis: the PSYCHAE Study. J Eur Acad Dermatol Venereol 2007; 21: 1161-9.

30. Szepietowski J, Adamski Z, Chodorowska G, et al. Leczenie łuszczycy zwyczajnej - rekomendacje ekspertów Pol- skiego Towarzystwa Dermatologicznego. Część I: łuszczyca łagodna, łuszczyca wieku dziecięcego [Diagnostics and treatment of psoriasis vulgaris: guidelines of the Polish Dermatological Society. Part I: mild psoriasis, psoriasis in children]. Przegl Dermatol 2012; 99: 83-96.

31. Cohen J. Statistical power analysis for the behavioral sciences. Hillsdale, Erlbaum 1988.

32. Smart Richman LS, Leary MR. Reactions to discrimination, stigmatization, ostracism, and other forms of interpersonal rejection: a multimotive model. Psychol Rev 2009; 116: 365-83.

33. Young M. The psychological and social burdens of psoriasis. Dermatol Nurs 2005; 17: 15-9.

34. Weiner B, Perry RB, Magnussen J. An attributional analysis of reactions to stigmas. J Pers Soc Psychol 1988; 55: 738-48.

35. Weiner B. On sin and sickness: a theory of perceived responsibility and social motivation. Am Psychol 1993; 48: 957-65.

36. Picardi A, Mazzotti E, Gaetano P, et al. Stress, social support, emotional regulation, and exacerbation of diffuse plaque psoriasis. Psychosomatics 2005; 46: 556-64.

37. Buote VM, Wilson AE, Strahan EJ, et al. Setting the bar: divergent sociocultural norms for women's and men's ideal appearance in real-world contexts. Body Image 2011; 8: 322-34.

38. Grabe S, Ward LM, Hyde JS. The role of the media in body image concerns among women: a meta-analysis of experimental and correlational studies. Psychol Bull 2008; 134: 460-76.

39. Striegel-Moore RH, Silberstein LR, Rodin J. Toward an understanding of risk factors for bulimia. Am Psychol 1986; 41: 246-63.

40. Janowski K, Steuden S, Pietrzak A, et al. Social support and adaptation to the disease in men and women with psoriasis. Arch Dermatol Res 2012; 304: 421-32. 